\title{
High Performance Positive Electrolyte with Potassium Diformate (KDF) Additive for Vanadium Redox Flow Batteries
}

\author{
Xiaoyan Wei ${ }^{1}$, Gang Wang ${ }^{*}, 2$ Feng Li $^{2}$, Jie Zhang ${ }^{2}$, Jinwei Chen ${ }^{2}$, Ruilin Wang ${ }^{*}, 2$ \\ ${ }^{1}$ College of Chemistry, Sichuan University, China \\ ${ }^{2}$ College of Materials Science and Engineering, Sichuan University, China \\ *E-mail: electrowg100@scu.edu.cn; rl.wang@scu.edu.cn
}

Received: 2 October 2021 / Accepted: 7 November 2021 / Published: 6 December 2021

\begin{abstract}
Vanadium redox flow batteries (VRFB) are considered as one of the auspicious candidate for energy storage application. However, the low solubility and poor thermal stability of the positive electrolyte as technical bottlenecks restrict the application of VRFB. Here, we present potassium diformate (KDF) that could significantly improve the performance of the $\mathrm{V}(\mathrm{V})$ electrolyte. The precipitation time of the electrolyte with KDF has prolonged at high temperature compared with the pristine. The electrochemical activity of the electrolyte has been enhanced significantly, and the corresponding cycle stability of the battery is also remarkably increased. Results revealed that the energy efficiency of battery with $\mathrm{V}(\mathrm{V})$ electrolyte containing $\mathrm{KDF}$ is higher than that of the pristine during cycling tests.
\end{abstract}

Keywords: VRFB; positive electrolyte; additive; potassium diformate

\section{$\underline{\text { FULL TEXT }}$}

(C) 2022 The Authors. Published by ESG (www.electrochemsci.org). This article is an open access article distributed under the terms and conditions of the Creative Commons Attribution license (http://creativecommons.org/licenses/by/4.0/). 